\title{
SIMULATION OF COMPONENTS MIXING IN ORDER TO DETERMINE RATIONAL PARAMETERS OF WORKING BODIES
}

\author{
Igor Stadnyk', Tatiana Vitenko', Paweł Droździel², Andrij Derkach \\ 1 Department of Food Technologies Equipment, Ternopil Ivan Puluj National Technical University, 56 Rus'ka St., \\ 46001 Ternopil, Ukraine, e-mail: vitenko@tstu.edu.ua \\ 2 Faculty of Mechanical Engineering, Lublin University of Technology, 36 Nadbystrzycka St., 20-618 Lublin, \\ Poland, e-mail: p.drozdziel@pollub.pl
}

Received: 2016.06.04 Accepted: 2016.07.05 Published: 2016.09.01

\begin{abstract}
One of important things in the production of vitally foods is bakery industry. The quality of baked goods can be achieved by improving the quality of dough kneading. In order to achieve this goal a new structure of the working body and methods of mathematical and computer modelling are offered, aimed to determine the working body design factors and visualize the process. Mathematical models of the dependency of dough viscosity from working body structural features and the frequency of its rotation are made. The obtained models are used to determine rational values of controlled parameters. It has been found that for wheat dough mixing the use of equipment with pin working bodies is more preferable. One of them - the main one - is larger in diameter, and two others - supporting ones - are smaller, able to ensure effective implementation of first and second stages of components mixing. The necessity of changing rotation direction of working bodies is substantiated. At the initial stage of mixing it is necessary to ensure larger diameter pin heating and at the stage of plasticization - vice versa - smaller diameter pins heating.
\end{abstract}

Keywords: working body, non-Newtonian fluid, mixing, kneading, interpolation model.

\section{PROBLEM STATEMENT}

The analysis of existing equipment and technologies used by leading manufacturers of food industry shows that currently there is a tendency to create computer-controlled machines and integrated technologies. As such, there is small variety between granulators and differences are typically limited to geometric constraints i.e. length, screw diameter and specific screw element geometry [1]. However, it is worth emphasizing that working bodies of existing machines have constant and unchanged geometric shape. The advantages of this method are, continuity and short process time and high productivity and product quality [2]. In such machines only the speed of the drive shaft can be regulated. It is obvious that such technical solutions give nothing fundamentally new, but seriously complicate kinematics of the machine, its maintenance and management. Though, natural limitations associated with a speed of physical-chemical, biochemical and other processes in non-Newtonian fluids area serious obstacle to further development in this direction. Many mixing processes already reached or come close to its limit parameters. Attempts made to accelerate these processes through the intensification of machines running by increasing the operating parameters can lead to a significant deterioration in the quality of finished products.

The brief analysis of the characteristics and state of modern equipment and methods of components mixing shows that the problem of finding of new directions in food engineering, which 
partially or fully decide these problems are still extremely relevant. The mixing process is highly complicated with a number of affecting parameters, such as the particle properties, the structure and performance of the mixer, the mixing process parameters and the particle feeding order [3].

Through the experimental investigations $[4$, 5], it is shown that the degree of mixing can be significantly increased by the optimization of the equipment. However, in these studies the mixing performance of the particles was only assessed qualitatively not quantitatively and the information provided by the experimental study was very limited [3].

During mixing all phenomena can be considered in terms of physical-chemical properties that determine the speed of the process at the molecular level and in the local volume of the machine working chamber containing a sufficient number of dispersed environment inclusions. Therefore, the study of phenomena occurring in the machine working chamber or on its individual stages, is mainly determined by the structure of hydrodynamic flows. In this case, the base of processes modeling consists of mathematical descriptions of flows structure using typical flow hydrodynamic models $[6,7,8,9]$. These models are: ideal mixing model, ideal displacement, single and two parametric diffusion models, local model. Diffusion model describes flows with longitudinal and transverse particles (components) mixing, where the intensity is estimated by coefficients of longitudinal and transverse mixing or by dimensionless complex-number Re.

\section{THE ANALYSIS OF RECENT RESEARCHES AND PUBLICATIONS}

Currently enterprises mostly use machines with working bodies, designed as a spatial cylindrical or conical spiral with constant or variable winding pitch along the spiral. Such equipment, especially manufactured by leading European companies such as DIOSNA (Germany), KEMPER (Germany), Gostol (Slovenia), MEC (Italy), MASZ-GLIWICE (Poland) gives a very high quality environment. Vertical and horizontal spiral mixing of semi-finished products plasticizes the components.

In order to increase the efficiency of components mixing at an early stage (e.g. Non-Newtonian Fluid - dough kneading) and formed viscous

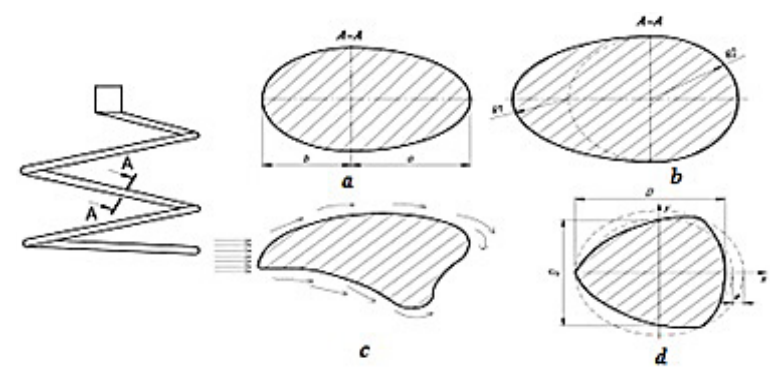

Fig. 1. Spiral working body with various forms of cross-section: a - profile with defined geometrical dimensions; $\mathrm{b}$ - ovoid; $\mathrm{c}$ - figure with sides made in the form of cycloid; $d$ - figure made in the shape of a triangular equilibrium loop

fluid mixing was offered to change the shape of the spiral cross-section of the working body (Fig. 1) $[10,11,12,13]$. The spiral cross-section is made in the shape of a profile with defined geometrical dimensions: ovoid; figure with sides made in the shape of cycloid; figure made in the shape of a triangular equilibrium loop. It was offered to implement spatial spiral in the form of interconnected outer and inner spirals (Fig. 2).

To ensure mixing uniformity, improve quality, increase productivity new design of the working body was offered, on which along spiral length mixing blades of the same length, but different in diameter are placed (Fig. 3) [13]. This creates the effect of additional vertical mixing through the formation of a vortex on the surface of the medium, providing its quality formation and increases productivity.

It should be noted that in working bodies designing a new breakthrough was made. In order to provide greater contact with the environment, process time reduction and therefore productivity increase a design of a new machine with a cylindrical working body was developed (Fig. 4).

One of the problems that arise when designing new equipment for mixing viscous masses, is
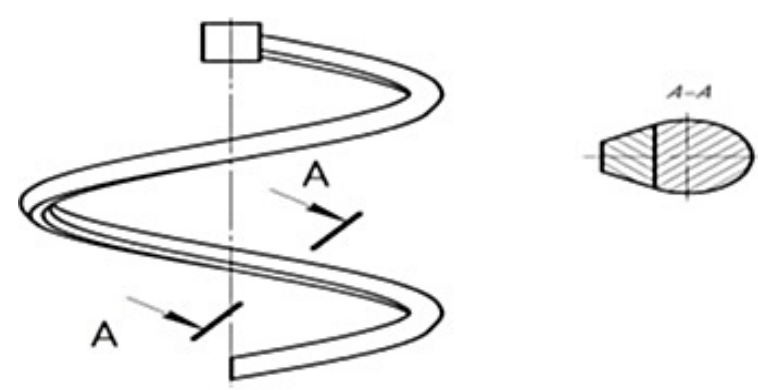

Fig. 2. Spiral working body, consisting of two connected spirals 


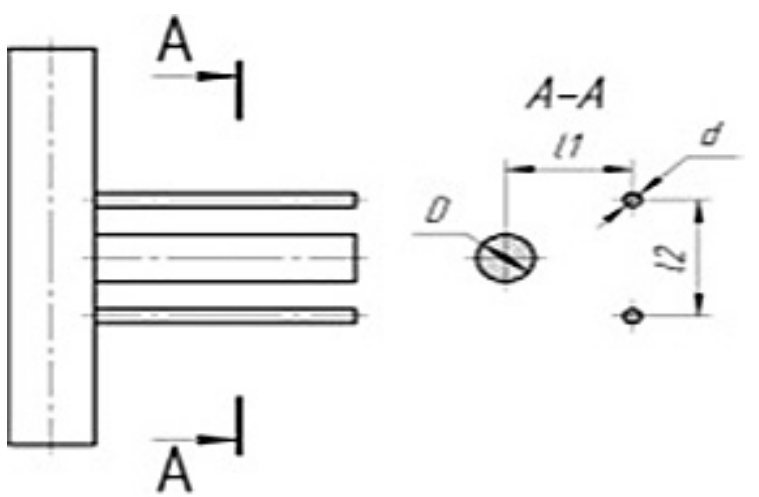

Fig. 3. Pin working body

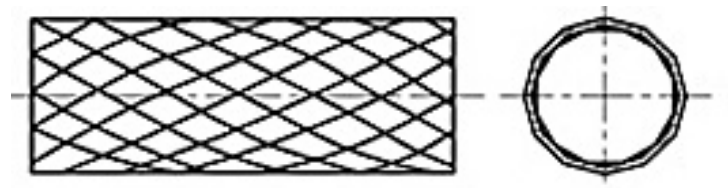

Fig. 4. Cylindrical working body with notches

the inability to predict the final result, to determine the quality of mixing with the existing „experimental technology“. The choice of the working body is made intuitively, then this choice is checked on the appropriateness by means of experimental studies. This, in turn, is effort, time and money consuming.

Failure to obtain information about the progress at any point in the working chamber, lack of theoretical data and practical experience significantly slowed down the work on the development of more efficient equipment. Computer modeling helps to eliminate the following problems: enables estimation of components distribution equitability, determination of energy parameters of the process on the basis of which it is possible to calculate specific work and determine the necessary power of drive station.

It is known that the process of components mixing is significantly affected by the viscosity $\eta$ and the current value index $\mathrm{n}$ in the motion equation describing the behavior of non-Newtonian pseudo-plastic fluid. Today still insufficiently investigated the change of rheological and hydrodynamic characteristics of dough during kneading, as it is impossible to determine the velocity of shear strain simultaneously at each point in the working chamber. The parameter $n$, which characterizes the degree of non-Newtonian environment behavior, is important to understand and accurately describe processes occurring during movement of non-Newtonian pseudo-plastic fluid (dough). Therefore, the mechanical effect on dough can occur in a wide range of deformation speeds. This inevitably affects its rheological properties, and sometimes even changing them on 1 ...2-order.

From theory [15] it is known that the best mixing occurs at considerable turbulence flow. The viscosity of non-Newtonian fluids and flow index $\mathrm{n}$ depend on shear-strain rate $[16,17]$. Therefore, it is essential to determine mutual dependence of the above mentioned parameters to obtain data on the occurrence of turbulence in the chamber during dough ingredients mixing. Aims of the work is define the parameters of dough-making and conduct mathematical and statistical processing of results to justify the parameters of the working organ. Computer modeling of components mixing workflow was conducted.

\section{METHODOLOGY OF EXPERMENTAL PART}

In order to obtain graphical dependency we will use known data [18], which are listed in Table 1. These data were processed with CurveExpert Professional 2.0.3 program, which allows simultaneously define both functional relationships between values (Fig. 5-6), and the correlation coefficient $r$ (the best index of equation fit is achieved when $r$ approaching 1. Sufficient for the equation perception adequacy index is in the range $0.8 \ldots 1$ ).

Table 1. The dependence of dough rheological parameters

\begin{tabular}{|c|c|c|}
\hline$\dot{\gamma}, \mathrm{s}^{-1}$ & $\tau, \mathrm{Pa}$ & $\eta, \mathrm{Pa} \cdot \mathrm{s}$ \\
\hline 0.4 & 130 & 310 \\
\hline 2.1 & 360 & 159 \\
\hline 10.4 & 820 & 73.5 \\
\hline 52.1 & 930 & 20 \\
\hline 260.4 & 1800 & 7.3 \\
\hline 1300 & 3800 & 3 \\
\hline
\end{tabular}

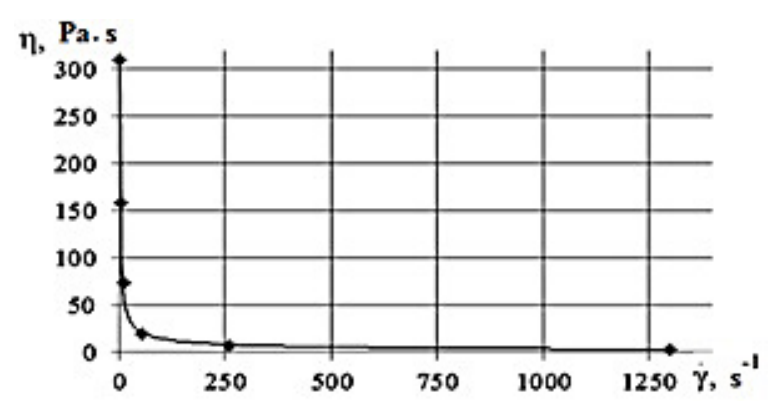

Fig. 5. The dependence of bread dough viscosity on the shear-strain rate 


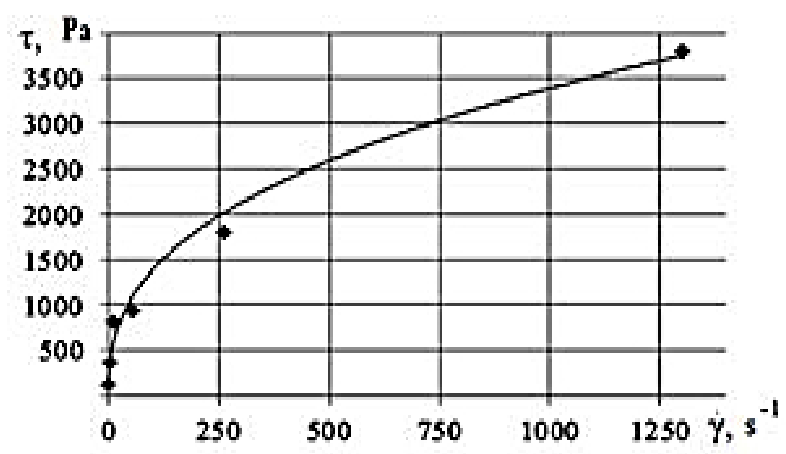

Fig. 6. The dependence of shear stress from deformation rate

Figure 5 shows that the dependence of dough viscosity on the shear-strain rate is nonlinear:

$$
\eta=206 \dot{y}^{0,45}
$$

As the dough is characterized by small values of the boundary shear stress $\tau_{0}$ and functional value of the latter is not taken into account, the obtained equation can be compared with the Herschel-Bulkley equation for which, in this case $K=206$ at $r=0.996$. To determine the current index $\mathrm{n}$ let us use the method offered by MetznerReed[19]. This method is based on the use of Muni-Rabinovich correlation for viscous shear on the wall.

Let us build a graphical relationship between shear stress $\tau$ and the rate of deformation $\dot{\gamma}$ according to the Table 1 (Fig. 6).

Functionally, this dependence is described by the equation: $\tau=212 \cdot \mathrm{y}^{0,4}$, with $\mathrm{r}=0.993$. Next, it is essential to specify the current index, which can be found with the help of equation [19]:

$$
\mathrm{n}=\mathrm{d} \ln \tau / \mathrm{dln} \mathrm{y}
$$

The dependence is graphically shown in Figure 7. This dependence is numerically described by the formula: $\mathrm{n}=0,539 \dot{\mathrm{y}}^{0,138}$, for which $r=$ 0.823 . According to the research the equation that most accurately describes the behavior of dough during kneading (at the stage of plasticization) was defined in the range of shear strain $0,4 \ldots 1300$ $\mathrm{s}^{-1}$ and viscosities $3 \ldots 310 \mathrm{~Pa} \cdot \mathrm{s}$, and the equation Herschel-Balkli:

$$
\tau-\tau_{0}=\mathrm{k} \cdot \dot{\mathrm{y}}^{\mathrm{n}}
$$

where: $\mathrm{k}=\eta \cdot \dot{\mathrm{y}}^{\mathrm{n}-1}$.

The obtained dependences allow to set the problem of dough kneading mathematical modeling reasonably on the stage of plasticization and eventually obtain adequate results.

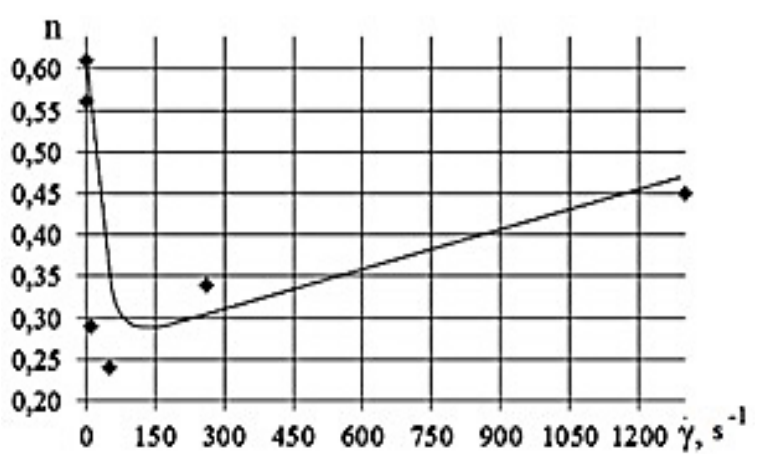

Fig. 7. The dependence of current index on strain rate

\section{MATHEMATICAL AND STATISTICAL RESULTS PROCESSING OF WORKING BODY PARAMETERS DETERMINATION}

The obtained results allow determining operating parameters in which the ratio of diameter and its velocity are in a certain range that ensures the highest efficiency [18]. Let us consider pin working bodies with diameter 20-30 $\mathrm{mm}$ at speeds of $250-300 \mathrm{rpm}$, that corresponds to a linear speed of $6.2-7.85 \mathrm{~m} / \mathrm{s}$ (Figure 3). To determine the design parameters 11 , 12 and rational mixing shaft rotation velocity $\mathrm{n}$, it is necessary to obtain interpolation model (regression equation), which establishes the impact of the above mentioned factors on the viscosity of the dough. As independent variables for this regression equation are selected working body rotation frequency and its design parameters are the following:

- $\mathrm{X}_{1}$ - distance from the blade with larger diameter to the blade with smaller diameter $(11), \mathrm{m}$;

- $\mathrm{X}_{2}$ - distance between the blades of smaller diameter (12), m;

- $\mathrm{X}_{3}$ - rotation frequency of mixing body $(\mathrm{n})$, $\mathrm{rev} / \mathrm{min}$.

For these variables is set the limitation (Table 2) based on the analysis of mixing body structure of industrial design.

Table 2. The limits of variation factors

\begin{tabular}{|l|c|c|c|}
\hline \multirow{2}{*}{\multicolumn{1}{|c|}{ Name }} & \multicolumn{3}{|c|}{ Factors } \\
\cline { 2 - 4 } & $\mathrm{X}_{1}[\mathrm{~m}]$ & $\mathrm{X}_{2}[\mathrm{~m}]$ & $\mathrm{X}_{3}[\mathrm{rpm}]$ \\
\hline Zero level & 0.022 & 0.022 & 350 \\
\hline Variability interval & 0.006 & 0.006 & 250 \\
\hline
\end{tabular}


Interpolation model is defined as:

$$
\begin{gathered}
y=b_{0}+\sum_{i=1}^{n} b_{i} x_{i}+ \\
+\sum_{j, i=1}^{n} b_{i j} x_{j} x_{i}+\sum_{i=1}^{n} b_{i i} x_{i}{ }^{2}
\end{gathered}
$$

where: $n$ - number of factors;

$\mathrm{b}_{0}, \mathrm{~b}_{\mathrm{i}}, \mathrm{b}_{\mathrm{ij}}, \mathrm{b}_{\mathrm{ii}}-$ regression coefficients,

$\mathrm{x}_{\mathrm{i}}, \mathrm{x}_{\mathrm{ij}}$ - coded values of factors.

To determine the coefficients of the regression equation let's conduct an experiment planned according to the second order type plan (orthogonal central composite plan), which scheme is given in Table 3. The choice of this plan is based on its simplicity: optimal planning matrix, the number of experiments is low (15), which allows quickly and accurately conduct experiments with high accuracy of final results.

For the calculation, we record the research results (determination of the viscosity) in Table 4. The coefficients of the regression equation determined by the formula [20]:

$$
\begin{gathered}
\mathrm{b}_{0}=\sum \sum_{\mathrm{u}=1}^{\mathrm{n}} \frac{\mathrm{y}_{\mathrm{u}}}{\mathrm{N}}, \mathrm{b}_{\mathrm{i}}=\frac{\sum \mathrm{x}_{\mathrm{iu}} \mathrm{y}_{\mathrm{u}}}{\sum \mathrm{x}_{\mathrm{iu}}^{2}}, \\
\mathrm{~b}_{\mathrm{ij}}=\frac{\sum \mathrm{x}_{\mathrm{iu}} \mathrm{x}_{\mathrm{ju}} \mathrm{y}_{\mathrm{u}}}{\sum\left(\mathrm{x}_{\mathrm{iu}} \mathrm{x}_{\mathrm{ju}}\right)^{2}}, \mathrm{~b}_{\mathrm{ii}}=\frac{\sum \dot{\mathrm{x}}_{\mathrm{iu}} \mathrm{y}_{\mathrm{u}}}{\sum\left(\dot{\mathrm{x}}_{\mathrm{iu}}\right)^{2}}
\end{gathered}
$$

Table 3. Experiment plan: determination of the dependency of dough viscosity on the design parameters of the working body and the frequency of rotation

\begin{tabular}{|c|c|c|c|c|c|c|}
\hline No. & $\mathrm{X}_{1}$ & $\mathrm{I}_{1,}$ & $\mathrm{X}_{2}$ & $\mathrm{I}_{2,}$ & $\mathrm{X}_{3}$ & $\mathrm{n}$ \\
\hline 1 & -1 & 0.016 & -1 & 0.016 & -1 & 100 \\
\hline 2 & 1 & 0.028 & -1 & 0.016 & -1 & 100 \\
\hline 3 & -1 & 0.016 & 1 & 0.028 & -1 & 100 \\
\hline 4 & 1 & 0.028 & 1 & 0.028 & -1 & 100 \\
\hline 5 & -1 & 0.016 & -1 & 0.016 & 1 & 600 \\
\hline 6 & 1 & 0.028 & -1 & 0.016 & 1 & 600 \\
\hline 7 & -1 & 0.016 & 1 & 0.028 & 1 & 600 \\
\hline 8 & 1 & 0.028 & 1 & 0.028 & 1 & 600 \\
\hline 9 & $-a$ & 0.015 & 0 & 0.022 & 0 & 350 \\
\hline 10 & $a$ & 0.029 & 0 & 0.022 & 0 & 350 \\
\hline 11 & 0 & 0.022 & $-a$ & 0.029 & 0 & 350 \\
\hline 12 & 0 & 0.022 & $a$ & 0.029 & 0 & 350 \\
\hline 13 & 0 & 0.022 & 0 & 0.022 & $-a$ & 46 \\
\hline 14 & 0 & 0.022 & 0 & 0.022 & $\mathrm{a}$ & 653 \\
\hline 15 & 0 & 0.022 & 0 & 0.022 & 0 & 350 \\
\hline
\end{tabular}

Description: $l_{l}, X_{1}$ - natural, $\mathrm{m}$, and coded values of linear size; $l_{2}, X_{2}$ - natural, $\mathrm{m}$, and coded values of linear size; $\mathrm{n}, X_{3}$ - natural, rev/min, and coded value of mixing body rotation velocity; a - star lever for 3-factor experiment $\mathrm{a}=1.215$.

Table 4. The results of studies on dough viscosity determination

\begin{tabular}{|c|c|c|c|c|}
\hline № & $\eta_{1}$, Pa·s & $\eta_{2}$, Pa·s & $\eta_{3}$, Pa·s & $\eta_{\text {cp }}$, Pa·s \\
\hline 1 & 84 & 85 & 87 & 85.3 \\
\hline 2 & 90 & 91 & 92 & 91 \\
\hline 3 & 100 & 101 & 102 & 101 \\
\hline 4 & 110 & 111 & 112 & 111 \\
\hline 5 & 85 & 85 & 86 & 85.3 \\
\hline 6 & 82 & 84 & 85 & 83.6 \\
\hline 7 & 77 & 79 & 80 & 78.6 \\
\hline 8 & 76 & 78 & 79 & 77.6 \\
\hline 9 & 83 & 84 & 85 & 84 \\
\hline 10 & 86 & 86 & 87 & 86.3 \\
\hline 11 & 90 & 92 & 93 & 91.6 \\
\hline 12 & 69 & 70 & 71 & 70 \\
\hline 13 & 68 & 68 & 69 & 68.3 \\
\hline 14 & 65 & 66 & 67 & 66 \\
\hline 15 & 66 & 67 & 68 & 67 \\
\hline
\end{tabular}


The obtained values of regression: $b_{0}=66.7$, $\mathrm{b}_{1}=1.44, \mathrm{~b}_{2}=-0.3, \mathrm{~b}_{3}=-6.01, \mathrm{~b}_{12}=0.62, \mathrm{~b}_{13}=-2.29$, $b_{23}=-6.04, b_{11}=12.52, b_{22}=9.61, b_{33}=0.33$. The significance of the coefficients was examined under the condition:

$$
\begin{aligned}
& t_{i}>t_{T}\left(t_{T}=2.0423 \text { inq }=\right. \\
& =0.05, f=(m-1) \cdot N=30
\end{aligned}
$$

where: $\mathrm{t}_{\mathrm{T}}-$ tabular Student's t-test [20],

$\mathrm{t}_{\mathrm{i}}-$ calculated Student's t-test,

$\mathrm{q}-$ level of significance,

$\mathrm{f}-$ number of freeness.

Standard deviation is:

$$
\mathrm{S}_{0}^{2}=\frac{1}{\mathrm{~N}_{0}-1} \sum_{\mathrm{k}=1}^{\mathrm{N}_{0}}\left(\mathrm{y}_{0 \mathrm{k}}-\overline{\mathrm{y}}_{0}\right)^{2}
$$

where: $\mathrm{N}_{0}$ - number of parallel experiments.

Dispersions of regression coefficients is:

$$
\begin{gathered}
\mathrm{S}_{\mathrm{b}_{0}}^{2}=\frac{\mathrm{S}_{0}^{2}}{\mathrm{~N}}, \mathrm{~S}_{\mathrm{b}_{\mathrm{i}}}^{2}=\frac{\mathrm{S}_{0}^{2}}{\sum \mathrm{x}_{\mathrm{iu}}^{2}}, \mathrm{~S}_{\mathrm{b}_{\mathrm{ij}}}^{2}= \\
=\frac{\mathrm{S}_{0}^{2}}{\sum\left(\mathrm{x}_{\mathrm{iu}} \mathrm{x}_{\mathrm{ju}}\right)^{2}}, \mathrm{~S}_{\mathrm{b}_{\mathrm{ii}}}^{2}=\frac{\mathrm{S}_{0}^{2}}{\sum\left(\dot{\mathrm{x}}_{\mathrm{iu}}\right)^{2}}
\end{gathered}
$$

As a result, we get values of Student's criteria: $\mathrm{t}_{1}=2.95, \mathrm{t}_{2}=0.62, \mathrm{t}_{3}=12.28, \mathrm{t}_{12}=1.09, \mathrm{t}_{13}=4.0$, $\mathrm{t}_{23}=10.55, \mathrm{t}_{11}=16.14, \mathrm{t}_{22}=12.36, \mathrm{t}_{33}=0.43$, according to which significant remain the following coefficients: $b_{0}=66.7, b_{1}=1.44, b_{3}=-6.01$, $b_{23}=-6.04, b_{11}=12.52, b_{22}=9.61$. Totally $1=5$ significant members. The regression equation in coded coordinates:

$$
\begin{aligned}
& \mathrm{y}=66.7+1.44 \mathrm{x}_{1}-6.01 \mathrm{x}_{3}- \\
& -6.04 \mathrm{x}_{2} \mathrm{x}_{3}+12.52 \mathrm{x}_{12}+9.61 \mathrm{x}_{22}
\end{aligned}
$$

Formula of coefficients transferring into natural coordinates is:

$$
\mathrm{X}_{\mathrm{i}}=\mathrm{x}_{\mathrm{i}} \cdot \Delta \mathrm{X}_{\mathrm{i}}+\mathrm{X}_{\mathrm{i}_{0}}
$$

where: $X_{i}$ - factors scores for the equations in natural coordinates,

$x_{i}$ - factors scores for the equation in coded coordinates,

$\Delta X_{i}-$ spacing variation for each factor,

$X_{i 0}$ - zero level of each factor.

Taking into account that in the natural coordinates $y=\eta(\mathrm{Pa} \cdot \mathrm{s}), X_{1}=l_{1}(\mathrm{~m}), \mathrm{X}_{2}=l_{2}(\mathrm{~m}) X_{3}=n$ (rpm), we get the interpolation model:

$$
\begin{gathered}
\eta=204.82+0.24 \mathrm{l}_{1}-0.42 \mathrm{n}- \\
-0.002 \mathrm{l}_{2} \mathrm{n}+19.4 \mathrm{l}_{12}+0.6 \mathrm{l}_{22}
\end{gathered}
$$

Dispersion of the model adequacy:

$$
\mathrm{S}_{\mathrm{da}}^{2}=\frac{1}{\mathrm{~N}_{0}} \sum_{\mathrm{n}=1}^{\mathrm{N}}\left(\mathrm{Y}_{\mathrm{u}}-\widetilde{\mathrm{Y}}_{\mathrm{u}}\right)^{2}=476
$$

where: $l$ - number of important members of the equation; $S_{\mathrm{da}}-$ dispersion adequacy; $N-$ number of experiments.
Rated value of Fisher criterion:

$$
\mathrm{F}_{\mathrm{p}}=\frac{\mathrm{s}_{\mathrm{da}}^{2}}{\mathrm{~s}_{0}^{2}} \ll \mathrm{F}_{\mathrm{T}}=4
$$

where: $F_{T}-$ tabular value of Fisher criterion; under conditions:

$$
\mathrm{q}=0.05, \mathrm{f}_{\mathrm{ad}}=\mathrm{N}-1=15-5=10, \mathrm{f}_{0}=3-1=2
$$

Thus, the obtained model adequately describes the process. Table 5 shows calculations results of coefficients significance, standard deviation of the experiment and tests for adequacy of the equations. In order to find the points of function extremum we check the necessary and sufficient conditions for the extremum existence. For that end we take partial derivatives:

$$
\begin{aligned}
& \frac{\partial \mathrm{y}}{\partial \mathrm{x}_{1}}=1.44+25.04 \mathrm{x}_{1}-6.01 \mathrm{x}_{3}-6.04 \mathrm{x}_{2} \mathrm{x}_{3}+9.61 \mathrm{x}_{2}^{2} \\
& \frac{\partial \mathrm{y}}{\partial \mathrm{x}_{2}}=1.44 \mathrm{x}_{1}+19.22 \mathrm{x}_{2}-12.05 \mathrm{x}_{3}+12.52 \mathrm{x}_{1}^{2} \quad(15) \\
& \frac{\partial \mathrm{y}}{\partial \mathrm{x}_{3}}=-6.01+1.44 \mathrm{x}_{1}-6.04 \mathrm{x}_{2}+12.52 \mathrm{x}_{1}^{2}+9.61 \mathrm{x}_{2}^{2}
\end{aligned}
$$

Equating the last to zero and solving a set of equations, we get the value in coded form: $\mathrm{x}_{1}=$ $-0.25 ; \mathrm{x}_{2}=-0.51$ and $\mathrm{x}_{3}=-0.28$. To determine function maximum or minimum we count second order partial derivatives:

$$
\begin{gathered}
\frac{\partial^{2} \mathrm{y}}{\partial \mathrm{x}_{1}}=25.04-6.01 \mathrm{x}_{3}-6.04 \mathrm{x}_{2} \mathrm{x}_{3}+9.61 \mathrm{x}_{2}^{2} \\
\frac{\partial^{2} \mathrm{y}}{\partial \mathrm{x}_{2}}=19.22+1.44 \mathrm{x}_{1}-12.05 \mathrm{x}_{3}+12.52 \mathrm{x}_{1}^{2} \\
\frac{\partial^{2} \mathrm{y}}{\partial \mathrm{x}_{3}}=1.44 \mathrm{x}_{1}-6.04 \mathrm{x}_{2}+12.52 \mathrm{x}_{1}^{2}+9.61 \mathrm{x}_{2}^{2}
\end{gathered}
$$

Substituting the obtained values of variables, we get: $\partial^{2} \mathrm{y} / \partial \mathrm{x}_{1}=28.36 ; \partial^{2} \mathrm{y} / \partial \mathrm{x}_{2}=23 ; \partial^{2} \mathrm{y} / \partial \mathrm{x}_{3}=6$, all values are greater than zero, thus the obtained dependence is a function of the minimum. In a natural form the value is: $l_{1}=0.02 \mathrm{~m} ; l_{2}=0.019 \mathrm{~m}$ and $n=280 \mathrm{rev} / \mathrm{min}$.

The next step is to determine the diameter of the main $\mathrm{D}$ and auxiliary $\mathrm{d}$ mixing pins, taking into account the design parameters obtained previously. To find the regression equation, which describes the dependence of dough viscosity from the above mentioned factors, we construct a planning matrix for the full factorial experiment, considering nonlinearities and intercomponent interactions (Table 6).

The regression equation for two factors, taking into account the effects of even intercomponent interactions:

$$
\begin{aligned}
y=b_{0} & +b_{1} x_{1}+b_{2} x_{2}+b_{12} x_{1} x_{2} \\
& +b_{11} x_{12}+b_{22} x_{22}
\end{aligned}
$$


Table 5. Test for adequacy of regression equation

\begin{tabular}{|c|c|c|c|c|}
\hline № & $\mathrm{y}_{\mathrm{m}}$ & $\sum\left(\mathrm{y}_{\mathrm{m}}-\mathrm{y}_{\mathrm{i}}\right)^{2}$ & $\mathrm{y}_{\mathrm{t}}$ & $\sum\left(\mathrm{y}_{\mathrm{m}}-\mathrm{y}_{\mathrm{i}}\right)^{2}$ \\
\hline 1 & 85.3 & 4.6 & 88.82 & 12.2 \\
\hline 2 & 91 & 2 & 88.82 & 4.75 \\
\hline 3 & 101 & 2 & 100.9 & 8.04 \\
\hline 4 & 111 & 2 & 100.9 & 11.8 \\
\hline 5 & 85.3 & 0.66 & 88.8 & 12.6 \\
\hline 6 & 83.6 & 4.6 & 88.8 & 0.74 \\
\hline 7 & 78.6 & 4.6 & 76.8 & 0.74 \\
\hline 8 & 77.6 & 4.6 & 76.8 & 1.52 \\
\hline 9 & 84 & 2 & 85.23 & 1.2 \\
\hline 10 & 86.3 & 0.66 & 85.23 & 15.8 \\
\hline 11 & 91.6 & 4.66 & 80.9 & 18.8 \\
\hline 12 & 70 & 2 & 80.9 & 12.74 \\
\hline 13 & 68 & 0.66 & 74.05 & 22.92 \\
\hline 14 & 66 & 2 & 59.44 & 3.16 \\
\hline 15 & 67 & 2 & 66.75 & $\mathrm{~S}_{\mathrm{da}}=151$ \\
\hline
\end{tabular}

The regression equation coefficients we determine by the formula [20]:

$$
\begin{aligned}
& \mathrm{b}_{0}=\sum \mathrm{u}=1 \frac{\mathrm{y}_{\mathrm{u}}}{\mathrm{N}}, \mathrm{b}_{\mathrm{i}}=\frac{\sum \mathrm{x}_{\mathrm{iu}} \mathrm{y}_{\mathrm{u}}}{\sum \mathrm{x}_{\mathrm{iu}}^{2}}, \\
& \mathrm{~b}_{\mathrm{ij}}=\frac{\sum \mathrm{x}_{\mathrm{iu}} \mathrm{x}_{\mathrm{ju}} \mathrm{y}_{\mathrm{u}}}{\sum\left(\mathrm{x}_{\mathrm{iu}} \mathrm{x}_{\mathrm{ju}}\right)^{2}}, \mathrm{~b}_{\mathrm{ii}}=\frac{\sum \dot{\mathrm{x}}_{\mathrm{iu}} \mathrm{y}_{\mathrm{u}}}{\sum\left(\hat{x}_{\mathrm{iu}}\right)^{2}}
\end{aligned}
$$

where: $x_{i u}-$ value of variable in the appropriate column of experiment plan $\left(\mathrm{x}_{\mathrm{iu}}= \pm 1\right)$;

$\mathrm{y}_{\mathrm{u}}-$ the result of $\mathrm{u}^{\text {th }}$ experiment;

$\mathrm{N}$ - total number of experiments;

$\mathrm{u}$ - number of the experiment variant;

i - factor number;

$\mathrm{j}$ - factor number that is different from $\mathrm{i}$.

The obtained values of regression coefficients: $\mathrm{b}_{0}=87.5, \mathrm{~b}_{1}=-5, \mathrm{~b}_{2}=2.66, \mathrm{~b}_{11}=-3.7, \mathrm{~b}_{12}=8.75$, $b_{22}=1$. The significance of the coefficients was examined under condition:

$$
\begin{gathered}
\mathrm{b}_{\mathrm{i}}>\mathrm{t} \sqrt{\mathrm{S}_{\left(\mathrm{b}_{\mathrm{i}}\right)}^{2}} \mathrm{~b}_{\mathrm{i}}>1.97 \\
\overline{\mathrm{y}}_{\mathrm{u}}=\frac{\sum_{\mathrm{k}=1}^{\mathrm{m}} \mathrm{y}_{\mathrm{k}_{\mathrm{u}}}}{\mathrm{m}}
\end{gathered}
$$

where: $\mathrm{t}$ - tabular Student's criterion [20],

$q$ - the level of significance,

$\mathrm{f}$ - number of degrees of freeness.

To determine $S^{2} b_{i}$ it is necessary to calculate $\overline{\mathrm{y}}_{\mathrm{u}}=\left(\sum_{\mathrm{k}=1}^{\mathrm{m}} \mathrm{y}_{\mathrm{ku}}\right) / \mathrm{m}$ and determine:

1. Interlinear dispersion reproducibility of unit results:

$$
\mathrm{S}_{\mathrm{y}_{\mathrm{k}_{\mathrm{u}}}}^{2}=\frac{\sum_{\mathrm{k}=1}^{\mathrm{m}}\left(\mathrm{y}_{\mathrm{k}_{\mathrm{u}}}-\overline{\mathrm{y}}_{\mathrm{u}}\right)^{2}}{\mathrm{~m}-1}
$$

where: $\mathrm{k}$ - number of repetition in each row; $\mathrm{u}$ - line number in the experiment plan.

2. The average (arithmetic) value for the whole experiment dispersion reproducibility of unit result:

$$
\mathrm{S}_{\mathrm{y}_{\mathrm{k}}}^{2}=\frac{\sum_{\mathrm{u}=1}^{\mathrm{N}} \mathrm{S}_{\mathrm{y}_{\mathrm{k}_{\mathrm{u}}}}^{2}}{\mathrm{~N}}=8.91
$$

3. The average value for the whole experiment dispersion reproducibility of the process output average value:

$$
\mathrm{S}_{\overline{\mathrm{y}}}^{2}=\frac{\mathrm{S}_{\mathrm{y}_{\mathrm{k}}}^{2}}{\mathrm{~m}}=2.97
$$

Coefficients dispersion of the regression equation is:

$$
\mathrm{S}_{\mathrm{b}_{\mathrm{i}}}^{2}=\frac{\mathrm{S}_{\overline{\mathrm{y}}}^{2}}{\mathrm{~N}}=0.33
$$

The regression equation in coded coordinates is $y=87.5-5 x_{1}+2.66 x_{2}+8.75 x_{1} x_{2}-3.7 x_{12}$. Taking into account that for natural coordinates $\mathrm{y}=$ $\eta(\mathrm{Pa} \cdot \mathrm{s}), \mathrm{X}_{1}=\mathrm{D}(\mathrm{m}), \mathrm{X}_{2}=\mathrm{d}(\mathrm{m})$, and using the formula, we get the interpolation model:

$$
\begin{aligned}
\eta= & 116.4-0.96 \mathrm{D}+4.21 \mathrm{~d}+ \\
& +0.27 \mathrm{Dd}-0.057 \mathrm{D}_{2}
\end{aligned}
$$

The resulting regression equation (factor experiment) binds factor levels with the process output in the studied area of surface response. It allows defining - without additional experiments - the process output values within the studied area of surface response by interpolation.

It is necessary to make sure that the obtained regression equation with a sufficient degree of re- 
Table 6. The plan of the experiment and the results of studies on dependence determination of dough viscosity from diameters of main and auxiliary mixing pins

\begin{tabular}{|c|c|c|c|c|c|c|}
\hline № & $\mathrm{X}_{1}$ & $\mathrm{X}_{2}$ & $\mathrm{X}_{1} \cdot \mathrm{X}_{2}$ & $\mathrm{D}$ & $\mathrm{d}$ & $\mathrm{\eta}_{\mathrm{m}}$ \\
\hline 1 & -1 & -1 & +1 & 0.008 & 0.004 & 102 \\
\hline 2 & +1 & -1 & -1 & 0.024 & 0.004 & 73 \\
\hline 3 & -1 & +1 & -1 & 0.008 & 0.012 & 80.3 \\
\hline 4 & +1 & +1 & +1 & 0.024 & 0.012 & 87 \\
\hline 5 & 0 & 0 & 0 & 0.016 & 0.008 & 92 \\
\hline 6 & +1 & 0 & 0 & 0.024 & 0.008 & 78 \\
\hline 7 & -1 & 0 & 0 & 0.008 & 0.008 & 85 \\
\hline 8 & 0 & +1 & 0 & 0.016 & 0.012 & 91 \\
\hline 9 & 0 & -1 & 0 & 0.016 & 0.004 & 80 \\
\hline
\end{tabular}

Description: D, $\mathrm{X}_{1}$ - natural, $\mathrm{m}$, and coded values of larger diameter pin; $\mathrm{d}, \mathrm{X}_{2}$ - natural, $\mathrm{m}$, and coded values of smaller diameter pin.

liability (adequately) describes the process that is being studied, e.g. the degree of reproducibility of the process is commensurate with the degree of process equation adequacy. Such test is carried out on F- test or Fisher criterion, which needs the following calculations:

- Calculates the output $\hat{y_{u}}$ for each variant of the experiment on the regression equation, where are excluded insignificant members;

- Calculates the adequacy dispersion:

$$
\mathrm{S}_{\mathrm{ad}}^{2}=\frac{\sum_{\mathrm{u}=1}^{\mathrm{N}}\left(\widehat{\mathrm{y}}_{\mathrm{u}}-\overline{\mathrm{y}}_{\mathrm{u}}\right)^{2}}{\mathrm{~N}-\mathrm{N}^{\prime}}=18.5
$$

where: $N^{\prime}$ - number of significant coefficients in the regression equation.

Estimated value of Fisher criterion:

$$
\mathrm{F}_{\mathrm{p}}=\frac{\mathrm{s}_{\mathrm{da}}^{2}}{\mathrm{~s}_{\mathrm{yk} \mathrm{u}}^{2}} \leq \mathrm{F}_{\mathrm{T}}=5,79
$$

where: $\mathrm{F}_{\mathrm{T}}$ - tabulated Fisher criterion values; accepted under conditions:

$$
\mathrm{q}=0.05, \mathrm{f}_{\mathrm{ad}}=\mathrm{N}-1=9-4=5, \mathrm{f}_{0}=3-1=2
$$

Thus, the obtained model adequately describes the process. After testing the necessary and sufficient conditions for the extremum existence, by the method similar to the above mentioned, we obtain rational values of mixing pins diameters of experimental assembly: $\mathrm{D}=0.014$ $\mathrm{m} ; \mathrm{d}=0.005 \mathrm{~m}$.

Using the theory PFE we have received adequate regression equation dependence of viscosity from the design parameters of the working body and the frequency of its rotations. Thus, it was found that in order to obtain the smallest values of viscosity during dough kneading the distance between the working body pins should be $l_{1}=0.02 \mathrm{~m}, l_{2}=0.019 \mathrm{~m}$ and their diameters $\mathrm{D}=0.014 \mathrm{~m} ; \mathrm{d}=0.005 \mathrm{~m}$.

\section{CONCLUSIONS}

With the emergence of powerful software designed to solve hydrodynamic problems, it became possible to analyze and visualize processes that occur during dough kneading. When the problem is set correctly the use of such computer systems shortens the duration of studies and reduces their costs, and gives adequate results, as well as allows eliminating errors at the stage of developing a design (22). According to the orthogonal central composite plan are set dependence mathematical models of dough viscosity from the working body design parameters (the distance between them) and the frequency of its rotation. The obtained models are used to determine rational values of these controlled parameters.

For kneading of wheat dough, it is advisable to use equipment with pin working bodies, one of which - the main one - with larger diameter, and the other two - subsidiary - with smaller diameter and they are able to provide effective implementation of both the primary components mixing and plasticizing them. It is necessary to provide a change in the direction of the working body rotation: at the stage of initial mixing it is necessary to ensure that the flow first runs to the pin with larger diameter, and at the plasticizing stage on the contrary - to the pins with smaller diameter.

\section{REFERENCES}

1. Seema T. C., Rowson N. A., Ingrama A., Huang Z., Yub S., de Matas M., Gabbott I., Reynolds G. K: Twin screw granulation - A literature review. Powder Technology, 276, 2015, 89-102. 
2. Xiao X., Tan Y., Zang H., Jiang S., Wang J., Deng R., Cao G., Wu B.: Numerical investigation on the effect of the particle feeding order on the degree of mixing using DEM. Procedia Engineering 2015, 102, 1850-1856.

3. Brone D., Muzzio F.J.: Enhanced mixing in double-cone blenders. Powder Technology, 110, 2000, 179-189.

4. Cho J., Zhu Y., Lewkowicz K., Lee S.H., Bergman T., Chaudhuri B.: Solving granular segregation problems using a biaxial rotary mixer. Chemical Engineering and Processing: Process Intensification, 2012, (57-58), 42-50.

5. Strenk F.: Peremeshivanie i apparaty s meshalkami. Chimiya 1976 (in Russian).

6. Steffe J.F.: Rheological Methods in Food Process Engineering. $2^{\text {nd }}$ Edition, Freeman Press, 1996.

7. Golovnev I., Platov S.A.: The critical analysis of models of turbulence of laminar-turbulent transition and a role of diffusion by pressure fluctuations. In: FLUCOME 2009, 10th International Conference on Fluid Control, Measurements and Visualisation, Moscow, Russia, 17-21 August 2009, 1-11.

8. Wilcox D.C.: Turbulence modeling for CFD, 3rd Edition, DCW Industries, Inc. 2006.

9. Vasylkiv V.V., Stadnyk I.Y., Andrieshyn, P.P.: Pat. 48533 Ukraine, MPK A21C 1/00 Dough-kneading working body. Ternopilskiy derzhavnyi tekhnichnyi universytet imeni Ivana Pulyuya (in Ukrainian).

10. Vasylkiv V.V., Stadnyk I.Y., Radyk D.L.: Pat. 53029 Ukraine, MPK A21C 1/00 Dough-kneading working body.Ternopilskiy derzhavnyi tekhnichnyi universytet imeni Ivana Pulyuya (in Ukrainian).

11. Vasylkiv V.V., Stadnyk I.Y.: Pat. 53030 Ukraine, MPK A21C 1/00 Dough-kneading working body. Ternopilskiy derzhavnyi tekhnichnyi universytet imeni Ivana Pulyuya (in Ukrainian).

12. Vasylkiv V.V., Stadnyk I.Y.: Pat. 54141 Ukraine, MPK A21C 1/00 Dough-kneading working body. Ternopilskiy derzhavnyi tekhnichnyi universytet imeni Ivana Pulyuya (in Ukrainian).

13. Batrachenko O.V., Lytovchenko I.M., Semylit A.A., Batrachenko O.V.: Pat. 34390 Ukraine, MPK A21C 1/00 Dough-kneading working body (in Ukrainian).

14. Kuznetsov O.A., Voloshyn E.V., Sagitov R.F.: Reologiyapishevykh mass. Uchebnoeposobie, Orenburg, GOU OGU, 2005 (in Russian).

15. Uilkinson U.L.: Non-Newtonian fluids. Mir, 216, 1964 (in Russian).

16. Valentas K.D.: Food engineering. In: Spravochnik s Primeramiraschetov. St. Petersburg: Professiya, 2004 (in Russian).

17. Shpak M.S.: $\mathrm{PhD}$ dissertation (DSc): 05.18.12, Kiev, 2015 (in Ukrainian).

18. Puchkova L.I.: Laboratornyi praktik umpotekhnologii hlebopekarnogo proizvodstva. In: Legkayai pishevaya promyshlennost, 1982 (in Russian).

19. Astarita A.: Osnovy gidromekhaniki neniytonovskikh zhydkostey. Mir, 1978 (in Russian).

20. Bondar A.G.: Planirovanie eksperimenta v khimicheskoy tekhnologii. Statiykha K., 1976 (in Russian). 